\title{
Experimental Study of Energy Consumption Variation in Recurring Driving Trips
}

Joern Adermann, Julian Kreibich and Markus Lienkamp

Institute of Automotive Tech., Technical University of Munich, Garching 85748, Germany

\begin{abstract}
With a growing consumer market of battery electric vehicles, customers' demand for technology and features is on the rise. The range and, to a certain extent, the range estimation will play a key factor in customers' purchase decisions. In order to guarantee a precise range estimation over the usage life of battery electric vehicles, a method is presented that combines adaptive filter algorithms with statistical approaches. The statistical approach uses recurring driving cycles over the lifetime in order to derive the aging status of the traction battery. It is implied that the variance of the energy usage of these driving cycles is within certain bounds. This fact should be proven by an experimental case study. The dataset used in this paper is open to the public.
\end{abstract}

Key words: $\mathrm{SOH}$ (state of health) estimation, traction battery, battery electric vehicle, recurring cycles, energy consumption.

\section{Introduction}

A key factor for the breakthrough of e-mobility into private automotive markets is an improved operational range and reliable range estimation algorithms $[1,2]$. The user acceptance of a BEV will significantly decrease if the car owner cannot rely on the range used for the route calculation. In order to face this problem, much scientific effort was taken to minimize the uncertainties of the range estimation. The uncertainty of the available energy - SOC (state of charge) - and the degradation effects - $\mathrm{SOH}$ (state of health) - of the traction battery is still a great challenge today. The accuracy depends on precise parameters and precisely integrated measuring technology and requires, to some extent, a significant amount of calculational power. These circumstances lead to high expenses when mass-producing BEVs. In order to minimize costs, a new method for $\mathrm{SOC} / \mathrm{SOH}$ determination is introduced: the CCM (commuter's cycle monitoring) [3, 4]. The method combines a Kalman filter in order to estimate the SOC with a historical data approach in order to update the degradation parameters $(\mathrm{SOH})$. A trend of

Corresponding author: Joern Adermann, M.Sc., research fields: prototyping of electric vehicles, battery system engineering, state estimation, Kalman filter. degeneration is derived from recurring driving cycles - e.g. the cycle of a commuter. An automatic comparison of these cycles derives the actual aging status of the LITB (lithium ion traction batteries). This information is used to update the parameters of the Kalman filter for SOC estimation. Recurring driving cycles, performed over the lifetime of a BEV, are implied [5]. The implementation and validation of the CCM method is the subject of ongoing research. Furthermore, it is implied that the variation of recurring driving cycles, taking account of different environmental conditions, is under a certain limit.

The following paper presents an experimental study on the variation of a characteristic commuter cycle that is derived from published driving behavior $[2,6]$. Multiple, identical driving routes were performed with a test BEV extended by an energy measurement setup. In Chapter 2, the state of the art regarding SOC and $\mathrm{SOH}$ estimation is characterized. The test vehicle and the measuring system are described in Chapter 3. A detailed description of the experiment and procedure is given in Chapter 4. The results discussed in Chapter 5 outline the limits of variation. It is shown that the theoretical approach of CCM could show promising results in a real driving environment. The raw data of 
the experiment (including the driving route, the energy consumption for traction and auxiliaries) are open to the public (refer to Chapter 6).

\section{Related Work}

The calculation and estimation of the internal states of LITB has been investigated in previous decades. Plett introduced a series of three papers [7-9] in 2004 that showed promising solutions for estimating both the SOC and the SOH of LITBs. Estimating the SOC using an adaptive filter approach is considered state of the art.

In Refs. [10, 11], well-structured benchmarks of different $\mathrm{SOH}$ estimation approaches can be found. The techniques are divided into experimental techniques and adaptive methods. For online implementation (no up- or downlink to an external server), only the adaptive model-based methods are outlined by the authors. Experimental techniques using direct measurements are neglected because of costs in this paper. Data driven experimental techniques are neglected because of the need for an external data connection. Furthermore, the accuracy of experimental techniques is rather low [10].

Utilizing adaptive methods on the $\mathrm{SOH}$ problem is still a great challenge. A guaranteed convergence of the time-discrete parameter estimators (Joint-Kalman filter, dual Kalman filer and Spherical Simplex Kalman filter) cannot be proven. Moreover, not only the convergence, but also the significant amount of calculation and parameterization effort is a disadvantage of these methods. A further overview based on adaptive filter algorithms is provided by Refs. [10, 11]. CCM presents a promising combined method of using an adaptive model based approach (Extended Kalman filter) for $\mathrm{SOC}$ and a data driven approach for $\mathrm{SOH}$ estimation without the use of external data. Only the characteristics of completed recurring driving trips are calculated. This enables a low cost implementation because no extra computational power is needed during operation. A low standard deviation of the recurring trips is a prerequisite in order to guarantee the reliability of the method.

\section{System Description}

\subsection{Test Vehicle}

The test vehicle used in the experiments is a first generation Volkswagen e-Golf. It is a series vehicle with a permanent, magnet-synchronous machine, and front-wheel drive. The e-Golf has an empty weight of $1,510 \mathrm{~kg}$, accelerates from $0-100 \mathrm{~km} / \mathrm{h}$ in $10.4 \mathrm{~s}$, and can reach a maximum speed of $140 \mathrm{~km} / \mathrm{h}$. The drag coefficient is given as 0.281 , the front surface with $0.615 \mathrm{~m}^{2}$, and the rolling resistance coefficient with 0.0065 . The combined power consumption in the NEDC (New European driving cycle) is $12.7 \mathrm{kWh} / 100$ $\mathrm{km}$. This results in an operational range of $190 \mathrm{~km}$. Table 1 provides an overview of the vehicle and its drive train.

\subsection{Measuring Equipment}

The test vehicle is equipped with the following high-precision measuring system. In order to evaluate the traffic situation and the driving behavior on the

Table 1 Specification of the test vehicle.

\begin{tabular}{ll}
\hline Vehicle & Volkswagen e-Golf \\
Type & $190 \mathrm{~km}$ (NEDC) \\
Range & $140 \mathrm{~km} / \mathrm{h}$ \\
Top speed & $1,510 \mathrm{~kg}$ \\
Empty weight & $12.7 \mathrm{kWh} / 100 \mathrm{~km}$ (NEDC) \\
Standard consumption & \\
Motor & Permanent synchronous \\
Technology & $85 \mathrm{~kW}(115 \mathrm{HP})$ at $3,000 \mathrm{RPM}$ \\
Power & $270 \mathrm{Nm}$ \\
Torque & 9.76 \\
Gear ratio & Max. 12.000 RPM \\
Revolutions & \\
Battery & Panasonic/Sanyo, NMC \\
Cell type & 264 \\
No of cells & $88 \mathrm{serial}, 3$ parallel \\
Circuitry & $323 \mathrm{~V} \mathrm{nominal}$ \\
Voltage & $75 \mathrm{Ah}$ \\
Capacity & $21.2 \mathrm{kWh}$ nominal \\
Energy & $68 \mathrm{Wh} / \mathrm{kg}$ \\
Energy density &
\end{tabular}


reference route, the longitudinal dynamics of the vehicle must be detected. The GPS (global positioning system) provides a simple way to determine the position. For this, the high-sensitivity GPS receiver, CANgpsG.i.n., $1 \mathrm{~Hz}$ from Garmin with a CAN (controller area network) interface is installed on the vehicle roof. This records the following characteristics: date and time, vehicle position (geographical length, width and height), speed and direction. With a $12 \mathrm{~V}$ supply voltage, its current consumption is $80 \mathrm{~mA}$. The GPS is accurate to within $15 \mathrm{~m}$ in $95 \%$ of cases.

In order to measure the energy consumption for traction and auxiliaries, the HV-battery voltage is continuously recorded. Likewise, two current sensors, one for the auxiliary consumption and one for the traction, are installed. The electricity consumption of the air-conditioning unit is recorded by a LEM energy sensor HTR 50-SB, which is designed for measuring ranges of $\pm 100 \mathrm{~A}$ and a nominal current of $50 \mathrm{~A}$. The electricity consumption of the traction unit is recorded by a LEM HTR 500-SB, which is designed for measuring ranges of $\pm 1,000 \mathrm{~A}$ and a nominal current of 500 A. Both sensors measure the current at a frequency of $10 \mathrm{kHz}$. The accuracy in the range of the nominal current is indicated by $\leq \pm 2 \%$ [12].

Fig. 1 provides an overview of the test vehicle and the measuring system.

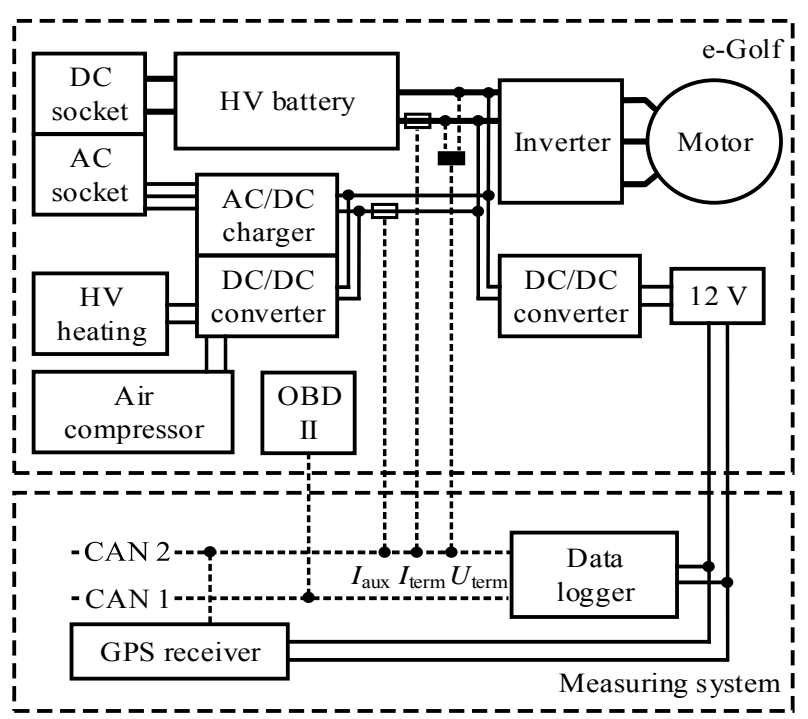

Fig. 1 Schematic overview of test vehicle and measuring system.
The system structure can be divided into the measuring system and the test vehicle (Volkswagen e-Golf). The main component of the vehicle is the HV battery, which can be loaded via a DC or an AC voltage socket; whereby, the AC voltage has to be converted to $\mathrm{DC}$ voltage via an AC/DC charger. Behind the AC/DC charger, the first current sensor is integrated to measure the charge and auxiliary current. In addition, a DC/DC converter is integrated in the battery charger, which supplies the electric air compressor and the HV-heating. Further, the second current sensor and the internal voltage measure both, the inverter and the DC/DC converter power. The inverter converts the direct current of the HV battery into three-phase alternating current with variable frequency and amplitude, thus providing the desired torque at the electric motor. The inverter of the e-Golf uses a voltage range of 255-360 $\mathrm{V}$ and delivers a maximum phase current of $430 \mathrm{~A}$ [13]. The DC/DC converter is appended to the power electronics to supply the $12 \mathrm{~V}$ on-board power supply.

All the measuring equipment is interconnected by a CAN bus in the measuring system. This CAN transfers the data of all sensors and allows for simplistic data logging. All relevant data are transmitted on two separate CAN buses, both recorded by one data logger. The advantage of a single data logger is the simultaneous recording of the different measurement data, avoiding a subsequent data synchronization step. An overview of the complete measuring system and the interaction of the subsystems in the test vehicle can be seen in Fig. 1. In this figure, the dotted lines symbolize data transfer over a CAN bus and the solid lines symbolize two or three-phased current flow. The measured values of the two current sensors, the voltage tap, and the GPS signal are connected to CAN 2 via CAN interfaces. The communication of the OBD II interface runs via the separate CAN 1 in order to ensure a fault-free transfer. Final, the entire measurement data are collected on the data logger GL1000 by Vector. It requires a supply voltage of $12 \mathrm{~V}$, whereby its own current consumption is $55 \mathrm{~mA}$. Table 2 provides an 
Table 2 Accuracy of used sensors.

\begin{tabular}{|c|c|c|c|c|}
\hline Measuring equipment & & Measuring range & Accuracy & Current consumption \\
\hline Current sensor auxiliaries & LEM HTR 50-SB & $\pm 100 \mathrm{~A}$ & $\leq \pm 2 \%$ & $\begin{array}{l}\text { Max. } \\
20 \mathrm{~mA}\end{array}$ \\
\hline Current sensor battery & LEM HTR 500-SB & $\pm 1,000 \mathrm{~A}$ & $\leq \pm 2 \%$ & $\begin{array}{l}\text { Max. } \\
20 \mathrm{~mA}\end{array}$ \\
\hline GPS receiver & CANgpsG.i.n. & & $\begin{array}{l}1 \mathrm{~Hz} \\
0.01 \\
0.1 \mathrm{~km} / \mathrm{h}\end{array}$ & $80 \mathrm{~mA}$ \\
\hline Data logger & Vector GL1000 & & & $55 \mathrm{~mA}$ \\
\hline
\end{tabular}

overview of the sensors used in this study and their measurement accuracy.

\section{Experimental Setup and Procedure}

In the following Chapter, the experimental setup and procedure will be described. As stated in the introduction, the focus of this publication is the examination of the energy consumption in recurring driving trips to detect the energy variation in realistic driving trips. Multiple identical driving routes were performed with the test BEV, extended with the energy measurement setup described in Chapter 3. A very important requirement regarding the research of recurring driving trips is the underlying data basis. The information was collected from the suburban area north of Munich in the state of Bavaria, Germany. It provides the essential information of realistic driving behavior. The real driving profile was defined regarding standard cycles and various mobility studies in order to obtain a realistic illustration of a typical mobility pattern $[2,6]$. Furthermore, local conditions had to be considered. The framework conditions provide a circuit with start and finish in the city of Garching near Munich.

Fig. 2 provides an overview of the driven route. The inverted triangle indicates the start and the destination of the circuit. The route begins with a typical urban traffic section with numerous stops and a normal driving speed between $40-50 \mathrm{~km} / \mathrm{h}$ (dotted line). Afterwards, a short intercity section is driven at a speed between $70-100 \mathrm{~km} / \mathrm{h}$ (solid line) before the drive ends with the motor-way section and a maximum speed of $120 \mathrm{~km} / \mathrm{h}$ (dashed/dotted line). A higher speed would not be justified, as there is a speed limit on motorways in most European countries [14].

A route length of $18.79 \mathrm{~km}$ results when the given conditions are adapted. The share of urban, intercity and motorway travel is $67 \%, 22 \%$ and $11 \%$ respectively. The driver is required to comply with the applicable speed limits. All of this attempts to represent a typical commuter cycle on urban and rural roads in terms of top speed, acceleration, and total duration. A map matching is not necessary to improve the GPS position accuracy, since the standard deviation of the measured travel distance of all reference trips is only $13 \mathrm{~m}$ or $0.07 \%$ [15]. This resulted in the following speed profile shown in Fig. 3 with a length of 18.79 km and an average travel time of 1,589 s.

Fifty trips with a total driving distance of $939.5 \mathrm{~km}$ were conducted in order to obtain sufficient statistical safety $[16,17]$. The journeys took place in the period from December 2016 to March 2017 and, if possible, with sufficient daylight to avoid the additional

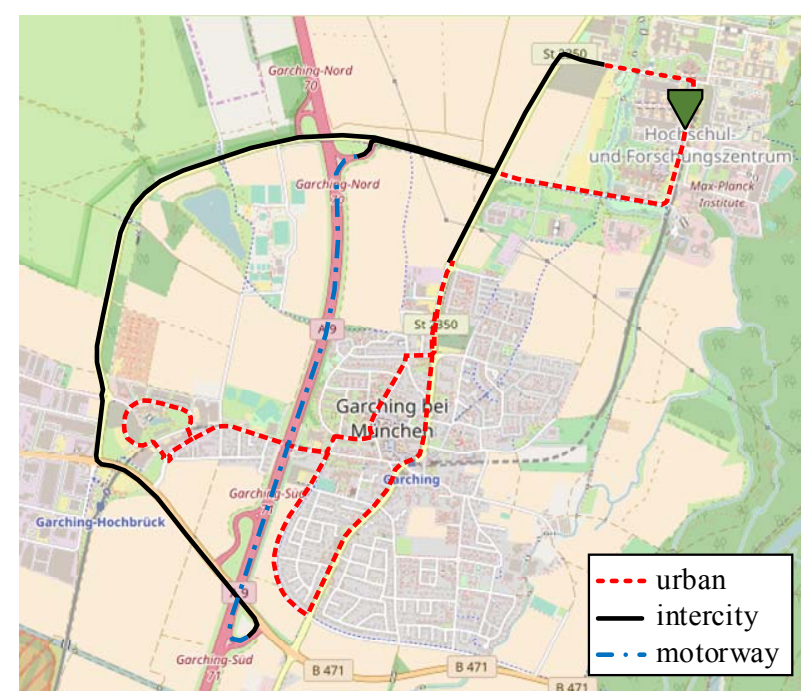

Fig. 2 Overview of the route. 


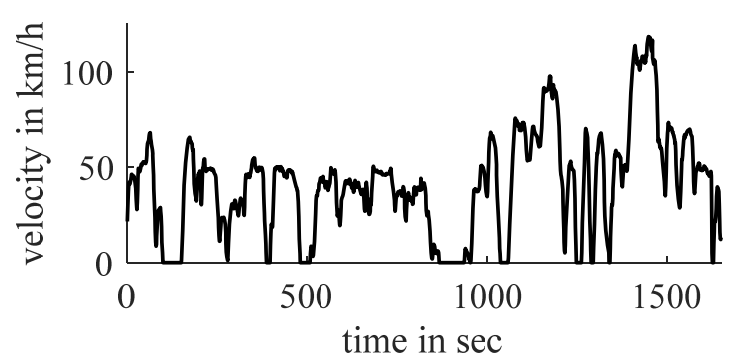

Fig. 3 Representative speed profile.

consumption by the headlights. The ambient temperature ranged from $-8{ }^{\circ} \mathrm{C}$ to $+19{ }^{\circ} \mathrm{C}$. As in real-life use, the vehicle has been operated over the entire SOC range. Furthermore, the trips took place in blocks with several trips in a row. In addition, the trips 27,28 and 49 were carried out with a payload of $100 \mathrm{~kg}$ and trip 50 carried a payload of $200 \mathrm{~kg}$ to examine a possible influence on the energy consumption by the targeted variation of the load weight. During the driving cycle, a height difference of $+/-91 \mathrm{~m}$ is overcome. Accordingly, the average slope is $+/-0.7 \%$. Since the reference route is a circuit, there is no overall difference between the start and the end, and thus, no potential energy must be applied. For this reason, the slope profile has no influence on the variance of the energy consumption since it is not a variable to the repeated travel of the same route profile. The average standing time of all trips is $12.1 \%$, the average low speed share $(<50 \mathrm{~km} / \mathrm{h}) 52.9 \%$, and the high speed share $(>90 \mathrm{~km} / \mathrm{h}$ ) $6.0 \%$. Table 3 provides an overview of the driving cycle parameters and their standard deviation.

The driving time and the average speed show a slight variance with a standard deviation of $5.7 \%$ and $5.5 \%$. The small proportion of the speed $>90 \mathrm{~km} / \mathrm{h}$ of $5.9 \%$, and the appropriate proportion of the speed $<50 \mathrm{~km} / \mathrm{h}$ of $54.8 \%$, correspond to the typical use of electric vehicles in the city [2]. The high standard deviations of the stops per kilometer with $28.3 \%$, the standing time with $30.1 \%$ and the speed $>90 \mathrm{~km} / \mathrm{h}$ with $18.2 \%$ are exceptional. Fig. 4 shows the average speeds and the shares of the speed ranges of the individual trips. The aforementioned sizable percentage deviation of the standing time and the range of the average speed of the individual trips are clearly recognizable.

The simultaneous variation of the average speed can be seen according to the varying speed shares. The gradations are clear, despite similar trips running on the same reference cycle under similar conditions. The measuring trips also cover a wide longitudinal dynamic range. They have a longitudinal acceleration in a range of $+/-3.5 \mathrm{~m} / \mathrm{s}^{2}$. With $16 \%$, the sector around a speed of $50 \mathrm{~km} / \mathrm{h}$ accounts for the largest share. Therefore, the measuring trips can be assumed to be representative and realistic.

Table 3 Relevant parameters of the driving cycles.

\begin{tabular}{lll}
\hline Parameter & Average value & Standard deviation \\
\hline Length & $18.79 \mathrm{~km}$ & $0.07 \%$ \\
Duration & $1,589 \mathrm{~s}$ & $5.7 \%$ \\
Average speed & $42.7 \mathrm{~km} / \mathrm{h}$ & $5.5 \%$ \\
Top speed & $117.2 \mathrm{~km} / \mathrm{h}$ & $3.3 \%$ \\
Acceleration & $0.46 \mathrm{~m} / \mathrm{s}^{2}$ & $6.6 \%$ \\
Max. acceleration & $2.47 \mathrm{~m} / \mathrm{s}^{2}$ & $11.0 \%$ \\
Deceleration & $0.42 \mathrm{~m} / \mathrm{s}^{2}$ & $7.1 \%$ \\
Number of stops & $0.471 / \mathrm{km}$ & $28.3 \%$ \\
Acceleration time & $31.7 \%$ & $4.7 \%$ \\
Standstill & $10.5 \%$ & $30.1 \%$ \\
Low speed & $54.8 \%$ & $7.7 \%$ \\
$<50 \mathrm{~km} / \mathrm{h}$ & & $18.2 \%$ \\
High speed & $5.9 \%$ & \\
$>90 \mathrm{~km} / \mathrm{h}$ & &
\end{tabular}

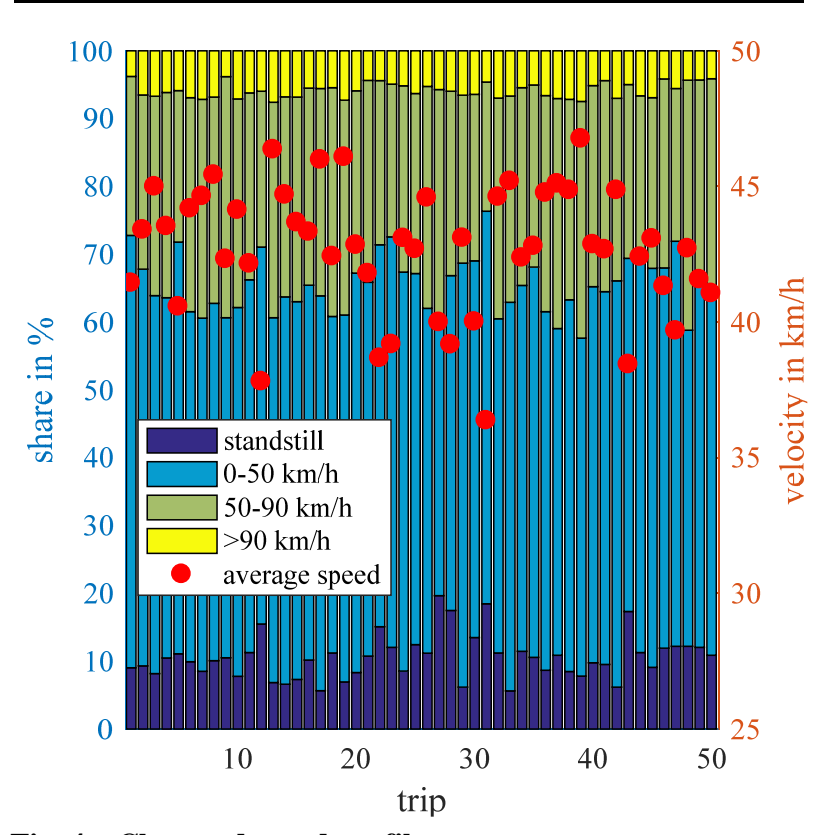

Fig. 4 Clustered speed profile. 


\section{Results}

After the representation and classification of the longitudinal dynamic characteristics of the reference trips in Chapter 4, the results discussed below outline the limits of the energy consumption variation. The overall aim in this study is to investigate the comparability and reproducibility of real-world commuter cycles. For this purpose, the energy of the electric drive train was primarily considered. The total energy consumption

$$
E_{\mathrm{Bat}}=\int_{t_{0}}^{t_{1}} U_{\mathrm{term}} \cdot I_{\mathrm{term}} \mathrm{d} t
$$

is measured via the voltage tap (terminal) $U_{\text {term }}$ and the current sensor $I_{\text {term }}$ on the HV battery.

In the present study, an average energy consumption of $16.3 \mathrm{kWh} / 100 \mathrm{~km}$ was measured over all reference runs. Fig. 5 shows the course of the energy consumption $E_{\text {Bat }}$ of each trip.

The energy consumptions of the individual trips have synchronous profiles over the reference distance. The average energy consumption is $3.06 \mathrm{kWh}$ and the standard deviation is $0.20 \mathrm{kWh}$, or $6.5 \%$, respectively. The outliers result from the following different special influences. The upper three trips 6, 13 and 27 have an increased energy consumption. The maximum value is measured with $3.63 \mathrm{kWh}$ during trip 6. Trips 6 and 13 have an above-average heating energy consumption since they took place at the beginning of a series of trips with a low ambient temperature. Trip 27 has an excessively high drive energy since it was carried out with a load of $100 \mathrm{~kg}$. Besides, the three trips 48, 49 and 50 differ significant downwards. The reason for this is a considerably higher outside temperature of $18{ }^{\circ} \mathrm{C}$ and $19{ }^{\circ} \mathrm{C}$ compared to the rest of the trips. The minimum value is $2.47 \mathrm{kWh}$, measured during trip 49 . This results in a lower heating energy consumption, a higher drive efficiency, and a corresponding higher recuperation energy. In the following detailed comparison of the reference trips, the outliers are not taken into account since they were not carried out under comparable conditions, as this is assumed using the method CCM.

The energy consumption $E_{\text {Bat }}$ of the individual reference runs with the average value of $3.06 \mathrm{kWh}$, which is shown in Fig. 6. The low standard deviation of $0.10 \mathrm{kWh}$, or $3.2 \%$, should be clearly highlighted.

Furthermore, the low bandwidth of $0.41 \mathrm{kWh}$ is shown. Thus, the maximum value is $3.30 \mathrm{kWh}$ at trip 16 and the minimum value is $2.88 \mathrm{kWh}$ at trip 20 . An average energy consumption of $16.3 \mathrm{kWh} / 100 \mathrm{~km}$ was measured from the reference drives. This results in an additional consumption of $28.3 \%$ compared to the NEDC specification of $12.7 \mathrm{kWh} / 100 \mathrm{~km}$, which also contains the charge losses. The reason for this was a higher drive power and the auxiliary energy, which is not taken into account in the NEDC. The corresponding shares of total energy consumption are therefore considered in more detail below. Fig. 7 shows the individual components of the energy consumption of all trips. The energy is composed of the share of the driving energy, the recuperation energy, and the heating energy. The drive train energy consumption

$$
E_{\text {trans }}=\int_{t_{0}}^{t_{1}} U_{\text {term }} \cdot\left(I_{\text {term }}-I_{\text {aux }}\right) \mathrm{d} t
$$

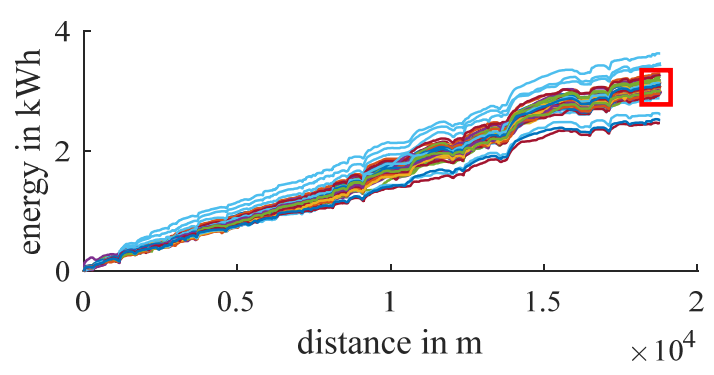

Fig. 5 Course of the energy consumption.

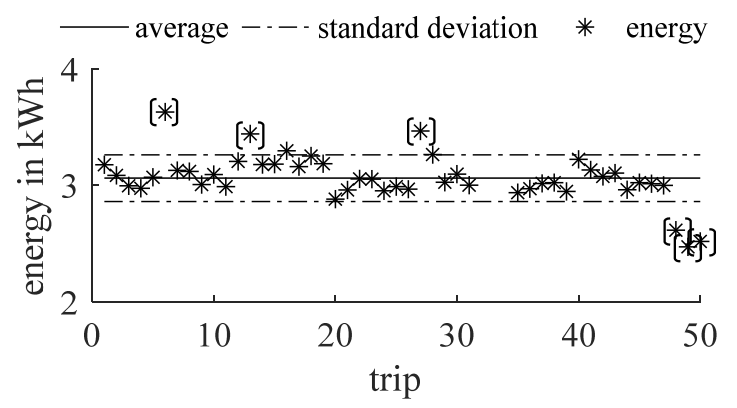

Fig. 6 Overall energy consumption. 


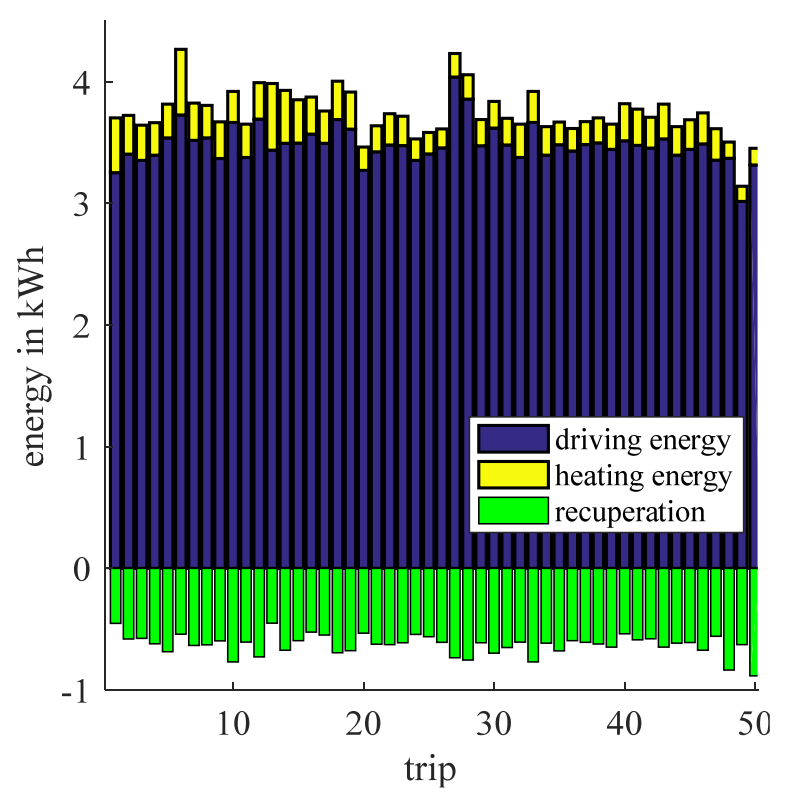

Fig. 7 Components of the energy consumption.

is measured via the voltage tap $U_{\text {term }}$ and the current sensor on the HV battery $I_{\text {term }}$.

The drive power is the largest with an average of $93 \%$, or $3.48 \mathrm{kWh}$. In addition, the heating consumes an average of $0.26 \mathrm{kWh}$, or $7 \%$. Recuperation can recover an average of $0.63 \mathrm{kWh}$ of the drive energy.

The low standard deviation of the drive energy of $2.8 \%$ should be noted. This is less than the standard deviation of the total energy with $3.2 \%$. The recuperation energy already has a significantly higher deviation of $9.7 \%$. The auxiliary energy consumption of the heating system surpasses this with a deviation of $24.1 \%$. However, due to its lower share of total consumption, the heating energy is less important with an absolute standard deviation of $0.06 \mathrm{kWh}$. Table 4 summarizes the results of the energy consumption of the reference runs, meaning without the effects of the special influences.

The recuperative driving energy has a great influence on the energy balance of a BEV, which is why it should be considered separately hereafter. During the reference trips, an average of $17.7 \%$ of the driving power could be recovered. Fig. 8 shows the recuperation energy of the individual reference runs with their standard deviation of $0.06 \mathrm{kWh}$ and $9.7 \%$, respectively.

One reason for the high standard deviation of $9.7 \%$ is the maximum recuperation power of $45 \mathrm{~kW}$. This limit is reached by 37 of the 40 reference trips under comparable conditions. The recuperation power is limited by the maximum charging current of the HV battery. This occurs with a fully charged battery and with a maximum deceleration to avoid damaging the battery pack. The drive train, including the motor with its maximum output of $85 \mathrm{~kW}$, would offer further potential. The reference trips 16, 24, 35, 40 and 43 were started with a fully charged battery. The recuperation energy of these trips amounts to an average of $0.564 \mathrm{kWh}$ or $16.3 \%$ of the drive energy. For the remaining reference runs, the average recuperation energy is $0.625 \mathrm{kWh}$ or $17.9 \%$ of the drive energy. This corresponds to a reduction in recuperation energy of $9.8 \%$ when the battery is fully charged and a total energy increase of $1.6 \%$.

However, the driving behavior mainly affects the standard deviation of the recuperation energy. An aggressive driving behavior contributes to increased drive-energy consumption with high average accelerations and decelerations. If the driving power in a reference trip increases by $10 \%$ or $0.33 \mathrm{kWh}$, the recuperation energy is increased by $26 \%$, or $0.14 \mathrm{kWh}$,

Table 4 Measurement results.

\begin{tabular}{lllc}
\hline Measurements & Value & \multicolumn{2}{c}{ Standard deviation } \\
\hline Overall energy & $3.06 \mathrm{kWh}$ & $0.10 \mathrm{kWh}$ & $3.2 \%$ \\
consumption & $3.47 \mathrm{kWh}$ & $0.10 \mathrm{kWh}$ & $2.8 \%$ \\
Driving energy & $0.63 \mathrm{kWh}$ & $0.06 \mathrm{kWh}$ & $9.7 \%$ \\
Recuperation energy & $0.26 \mathrm{kWh}$ & $0.06 \mathrm{kWh}$ & $24.1 \%$ \\
\hline
\end{tabular}

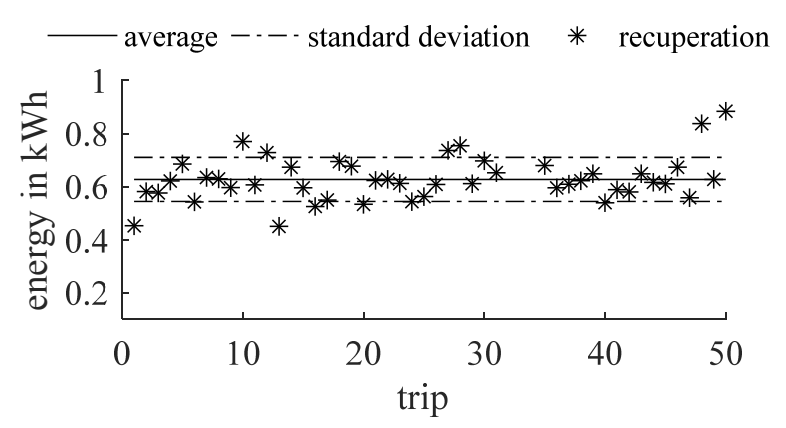

Fig. 8 Recuperation energy. 
respectively. Thus, the recuperation reduces the variance of the total energy consumption and increases the comparability of the individually recurring driving trips. However, a further increase in the drive energy, due to a more aggressive driving behavior with higher average accelerations or decelerations, will increasingly have an effect on the recuperation energy since, as described above, the percentage of the decelerations outside the maximum recuperation deceleration also increases.

\section{Conclusions}

The results show that under comparable ambient conditions, the energy consumption of recurring driving cycles is in a standard deviation of $3.2 \%$. Implying the fact that a $\mathrm{BEV}$ user carries out recurring cycles over the lifetime of the car, aging phenomena can be observed with a high certainty. These results are an important element for further work on the CCM approach. The dataset is available for download under the following link:

https://syncandshare.lrz.de/dl/fiLzvMkBBgh8kUzp cRL5MWoi/Dataset.zip

\section{Acknowledgments}

This work was supported by the Bavarian Research Foundation within the research project NEmo. We would like to thank Roman Sennenfelder from IAV $\mathrm{GmbH}$ for supporting the project in a great manner.

\section{Contributions}

J. A. initiated the work on CCM and developed the underlying concept. J. K. set up the measurement system and performed the reference cycles as part of his Master Thesis. J. K. evaluated the measuring data. M. L. made an essential contribution to the conception of the research project and revised the paper critically for important intellectual content. M. L. gave final approval of the version to be published and agrees to all aspects of the work. As a guarantor, M. L. accepts responsibility for the overall integrity of the paper.

\section{References}

[1] Hong, J., Park, S., and Chang, N. 2016. "Accurate Remaining Range Estimation for Electric Vehicles." In Proceedings of the Asia and South Pacific Design Automation Conference, 781-6.

[2] Pfriem, M. 2015. Analyse der Realnutzung von Elektrofahrzeugen in kommerziellen Flotten zur Definition einer bedarfsgerechten Fahrzeugauslegung. Karlsruhe: Scientific Publishing.

[3] Adermann, J., Brecheisen, D., Wacker, P., and Lienkamp, M. 2017. "Parameter Estimation of Traction Batteries by Energy and Charge Counting during Reference Cycles." In 2017 IEEE 86th Vehicular Technology Conference 7.

[4] Adermann, J., Wacker, P., Horlbeck, L., Baumann, M., and Lienkamp, M. 2016. "Alternative Methods for Detecting the Degeneration of Electric Drive Train Components." In Conference on Future Automotive Technology, 1-9.

[5] McKenzie, B. 2015. "Who Drives to Work? Commuting by Automobile in the United States: 2013."

[6] Infas and DLR. 2010. "MiD 2008-Mobilität in Deutschland 2008.".

[7] Plett, G. L. 2004. "Extended Kalman Filtering for Battery Management Systems of Lipb-based HEV Battery Packs_Part 1. Background.” J. Power Sources 134 (2): 252-61.

[8] Plett, G. L. 2004. "Extended Kalman Filtering for Battery Management Systems of Lipb-based HEV Battery Packs-Part 2. Modeling and Identification.” J. Power Sources 134 (2): 262-76.

[9] Plett, G. L. 2004. "Extended Kalman Filtering for Battery Management Systems of Lipb-based HEV Battery Packs-Part 3. State and Parameter Estimation.” J. Power Sources 134 (2): 277-92.

[10] Berecibar, M., Gandiaga, I., Villarreal, I., Omar, N., Van Mierlo, J., and Van den Bossche, P. 2016. "Critical Review of State of Health Estimation Methods of Li-Ion Batteries for Real Applications" Renewable and Sustainable Energy Reviews 56: 572-87.

[11] Waag, W., Fleischer, C., and Sauer, D. U. 2014. "Critical Review of the Methods for Monitoring of Lithium-Ion Batteries in Electric and Hybrid Vehicles." J. Power Sources 258 (September): 321-39.

[12] LEM Holding SA. 2017. "Current Transducer HTR 50 to 500-SB.” 3-5.

[13] Siebenpfeiff, W. 2015. Fahrerassistenzsysteme und Effiziente Antriebe. Stuttgart: Springer Vieweg.

[14] Draskoczy, M., and Mocsari, T. 1998. "Present Speeds and Speed Management Methods in Europe." In 9th International Conference Road Safety in Europe, 12.

[15] Grubwinkler, S., and Lienkamp, M. 2013. "A Modular 
and Dynamic Approach to Predict the Energy Consumption of Electric Vehicles." In Conference on Future Automotive Technology, 10.

[16] von der Lippe, P., et al. 2011. Wie groß muss meine Stichprobe sein , damit sie repräsentativ ist? Wie viele
Einheiten müssen befragt werden? Was heißt “Repräsentativität”? Essen: Discussionpaper.

[17] Kraft, C. 2011. Gezielte Variation und Analyse des Fahrverhaltens von Kraftfahrzeugen Mittels Elektrischer Linearaktuatoren im Fahrwerksbereich (German Edition). 